\title{
Short Communication: Sequence variation of DREB2 gene as a potential molecular marker for identifying resistant plants toward drought stress
}

\author{
DWI SETYO RINI \\ Research Center for Biology, Indonesian Institute of Sciences. Cibinong Science Center, Jl. Raya Jakarta-Bogor Km 46, Cibinong, Bogor 16911, \\ West Java, Indonesia. Tel.: +62-21-87907636 - 87907604, Fax.: +62-21-87907612, email: dwi.setyo.rini@lipi.go.id, dw.setyo19@ gmail.com
}

Manuscript received: 5 July 2018. Revision accepted: 14 February 2019.

\begin{abstract}
Rini DS. 2019. Short Communication: Sequence variation of DREB2 gene as a potential molecular marker for identifying resistant plants toward drought stress. Nusantara Bioscience 11: 35-43. Drought stress is the most destructive environmental factor affecting agricultural productions worldwide. Drought stress affects around 60 million hectares of agricultural land in Indonesia. Therefore, the selection of crops that can grow well and survive under drought is necessary to overcome the problem of decreased crop yield during stress conditions. DREB2 (Dehydration Responsive Element Binding2) belongs to the Transcription Factor (TF) gene families as a master regulator of plant responses under stress. Due to increased expression by stress, this gene can be used as a molecular marker to identify resistant plants toward drought. However, study the sequence variation of DREB2 is required to understand the character of this gene related to its function at a molecular level. The sequence of DREB2 in several plants was obtained from NCBI and aligned to determine the similarity of the regions. Even though variations were found in N-terminal of DREB2 sequences studied, there was a high similarity of the sequences in the DNA binding domain. It has been predicted that this domain is part of a conserved region in the sequence of DREB2 gene. This domain is then proposed to be used for primer designing purposes to study DREB2 gene expression between plant species.
\end{abstract}

Keywords: DREB2, drought stress, sequence variation

\section{INTRODUCTION}

As environmental constraints, drought stress can limit crop productivity due to its effect in impairing normal plant growth. Therefore, high yield productivity of crop under normal as well as under drought conditions is crucial for food security of the growing population. Plant, however, adapt to drought stress through a variety of physiological, biochemical, and molecular mechanisms at the cellular and whole organism levels (Basu et al. 2016).

Molecular analysis of plant responses toward drought stress is one of the most interesting subjects in the modern biological sciences (Hirayama and Shinozaki 2010). A better understanding of this molecular mechanism is fundamentally required to engineer the transgenic droughttolerant plants genetically. Through the availability of the complete genome sequence of some model plants, such as Arabidopsis thaliana and Oryza sativa, a number of genes have been described to respond to drought stress. These genes were identified by using genetic, reverse genetic, and molecular biology methods (Bartels and Sunkar 2005; Yamaguchi-Shinozaki and Shinozaki 2005).

Genes induced by drought stress can broadly be classified into two groups regarding its function. The first group contains the genes which the proteins encoded are designed as functional proteins. These proteins probably function as metabolic proteins for stress tolerance through protecting the cells from stress effects by the removal of toxic elements, restoration of cellular homeostasis, and eventual recovery of normal growth pattern. These proteins include water channel protein, proline, detoxification enzymes, antifreeze proteins, and late embryogenesis abundant (LEA) proteins (Shinozaki and YamaguchiShinozaki 2007; Gao et al. 2008; Jan et al. 2012). The second group is the genes which proteins encoded function as regulatory proteins involved in further regulation of signal transduction and stress-responsive gene expression. The proteins belonging to this group are calmodulinbinding protein, protein kinases, protein phosphatases, and transcription factors (Shinozaki and Yamaguchi-Shinozaki 2007).

DREBs (Dehydration Responsive Element Bindings) are important transcription factors (TFs) regulating the expression of many stress-inducible genes (Lata and Prasad 2011). TFs function to play an essential role in multiple abiotic stress responses through binding to regulatory elements in the promoter region of downstream stressresponsive genes, thereby promoting or suppressing its function (Mitsuda and Ohme-Takagi 2009; Nuruzzaman et al. 2013; Mun et al. 2017). DREB family of transcription factors which consist of two subfamilies, namely CBF/DREB1 (C-Repeat Binding Factor/Dehydration Responsive Element Binding1) and DREB2 (Dehydration Responsive Element Binding2) (Liu et al. 1998), are involved in two separate low temperature and dehydration signal transduction pathways, respectively (Nakashima et al. 2000; Sakuma et al. 2006). In Arabidopsis plant, DREB transcription factors binds to DRE/CRT (Dehydration- 
Responsive Element/C-Repeat) cis-elements which the conserved DNA-binding motif is $A / G C C G A C$ (YamaguchiShinozaki and Shinozaki 2005; Lucas et al. 2011) that function to modulate the expression of stress-responsive genes in an ABA-independent signaling pathway (Riechmann et al. 2000; Khan 2011) .

DREB2 was first identified in Arabidopsis plant. This gene was screened by using a yeast one-hybrid screen method and driven by using the CAMV35S promoter as the bait (Liu et al. 1998). Afterward, DREB2 homologous genes have been successfully isolated from many economically important cereal crops such as wheat, pearl millet, foxtail millet, and maize (Egawa et al. 2006; Qin et al. 2007; Agarwal et al. 2010; Lata et al. 2011). Temporal gene expression studies of DREB2 gene in various crops have revealed that this gene is not only induced by drought but also by heat and salinity (Liu et al. 1998; Sakuma et al. 2006). Their overexpression can significantly improve the stress tolerance of the transgenic plant. Overexpression of GmDREB2 in tobacco plant driven by $C A M V 35 S$ promoter showed an increased tolerance level of a plant towards drought (Chen et al. 2007). Moreover, transgenic canola plant containing Arabidopsis DREB2A confers tolerance to salinity stress (Shafeinie et al. 2014).

It has been widely known that variation of gene sequences presents within and among various plant populations (Gonzalez-Martinez et al. 2006; Arana et al. 2010; Constanzo and Jia 2010; Yi et al. 2018). Such variations, in turn, will also underlie genetic diversity between organisms. Many studies also indicate the presence of sequence variation in drought-responsive genes in a plant (Pomponio et al. 2013; Yu et al. 2013; Xia et al. 2017). In this study, however, we focused on analyzing the sequence variations of DREB2 transcription factor (TF) genes in plants related to their function as a master regulator to manage and organize the expression of downstream drought-responsive genes located in the ABAindependent signaling pathway.

\section{MATERIALS AND METHODS}

\section{Sequence materials}

Nucleotides and amino acids of DREB2 sequences tested in this study were obtained from the National Center for Biotechnology Information (NCBI) GenBank database (www.ncbi.nlm.nih.gov) in FASTA format. Only the complete cds (coding sequence) of DREB2 sequences from 42 species of monocotyledon and dicotyledon plants (Table 1) was used for data analysis.

\section{Data analysis}

Phylogenetic trees of DREB2 sequences on various plants studied were constructed by MEGA 7 tool (http: //www.megasoftware.net/mega.html) (Tamura et al. 2007) based on the distance matrix with the neighbor-joining $(\mathrm{NJ})$ method. The tree was drawn to scale, with branch lengths (next to the branches) in the same units as those of the evolutionary distances used to infer the phylogenetic tree. The evolutionary distances were computed using the p- distance method and were in the units of the number of base differences per site. All positions containing gaps and missing data were eliminated. The neighbor-joining (NJ) tree was performed to present the expected phylogenetic relationship of DREB2 gene among the tested plant species.

The multiple alignments of the nucleotide sequence of DREB2 were conducted by using BioEdit Sequence Alignment Editor (Hall 1999). The protein multiple sequences alignments of DREB2 was performed by using CLC sequence viewer 8 (CLC Bio, Aarhus Denmark). The result obtained will identify the homology region between the sequences studied. Then, the consensus sequences of the alignment results were calculated from multiple sequence alignment taking into account the quality value for each base.

\section{RESULTS AND DISCUSSION}

Since it was identified first in Arabidopsis plant (Liu et al. 1998), DREB2 gene has been recognized to contain a conserved AP2/ERF (APETALA2/Ethylene Responsive Factor) domain (Sakuma et al. 2002) which function was to recognize DRE (Dehydration Responsive Element) sequence (Mitsuda and Ohme-Takagi 2009). The AP2 domain consists of a three-stranded $\beta$-sheet and one $\alpha$-helix which is almost parallel to the $\beta$-sheet, and it contacts to the DNA sequence of gene target via Arg and Trp residues located in the $\beta$-sheet (Liu et al. 1998).

Sequence variation is one of necessity occurred during the adaptation process to various environmental conditions. Sequence variation is taken together with the environmental effect lead to the presence of diversity among organism. In this study, DREB2 sequences of plant species obtained from the NCBI database are varied both in length and in sequence. A systematic phylogenetic analysis was carried out on the basis of the nucleotide sequence of DREB2 gene in 42 plants obtained from the NCBI database. This phylogenetic tree was performed by MEGA 7 with the Neighbor-Joining (NJ) method. The result of phylogenetic analysis (Figure 1) shows that all the six subgroups of DREB2 gene can be easily classified in the plants tested. Sub-group A and B all consist of monocotyledon plants in the family of Poaceae. Interestingly, Triticum aestivum and Triticum turgidum that also belong to a member of the Poaceae family, are placed separately in the sub-group D and E, respectively. Both plants are in the same group with dicots plants, such as Glycine max and Coffea arabica. However, Agropyron mongolicum, a member of Poaceae plants, is distantly related to DREB2 of Triticum turgidum and clustered in the same region, subgroup E, like those from dicotyledon plants.

Multiple alignment sequence of cds (coding sequence) DREB2 (Figure 2) was performed in Poaceae plants with all the members are included in the clade (sub-group) A (Figure 1). Poaceae plants used in this alignment analysis are Saccharum officinarum (JQ736812.1), Sorghum bicolor (DQ403725.1), Setaria italica (NM_001310053.1), Hemarthria compressa (KC203598.1), Poa pratensis 
(AY553331.1), Aegilops biuncialis (FR719742.1), and Buchloe dactyloides (EF512460.1). It has been identified that the DREB gene contains the basic region and an acidic region in its $\mathrm{N}$-terminal and $\mathrm{C}$-terminal region, respectively. The basic region functions as a nuclear localization signal whereas an acidic region might play as an activation domain for transcription. Since the TFs only function in the nucleus, the regulation of their entry into the nucleus is mediated by NLS (Akhtar et al. 2012). However, its middle region functions as a negative regulatory domain in the regulation of DREB2 activity (Akhtar et al. 2012).

The result of multiple alignments performed by BioEdit Sequence Alignment Editor shows the sequence variation at the N-terminal domain (Figure 2.A). The homology region of DREB2 nucleotide is presented at the $\mathrm{C}$-terminal domain of the sequence (Figure 2C). However, a high similarity nucleotide sequence is also identified in the region located in between $\mathrm{N}$-terminal stretch which is rich in basic and hydrophilic residue and $\mathrm{C}$-terminal region capable of forming an $\alpha$-helix strand. The high similarity region of the nucleotide sequence indicates the conserved region of DREB2 gene (Figure 2B). Variation of a few nucleotides in this region is supposed to be critical for amino acid changes.

Table 1. List of plant species, NCBI accession number, and references for DREB2 analysis in this study

\begin{tabular}{|c|c|c|}
\hline Plant species & NCBI accession number & References \\
\hline Aegilops biuncialis & FR719742.1 & Yang et al. (2010) \\
\hline Aegilops speltoides & KF731665.1 & Tavakol et al. (2014) \\
\hline Aegilops tauschii & KF731663.1 & Tavakol et al. (2014) \\
\hline Agropyron mongolicum & MG385678.1 & Yu and Han (2017) \\
\hline Betula luminifera & KP245823.1 & Zhang (2014) \\
\hline Buchloe dactyloides & EF512460.1 & Hu et al. (2007) \\
\hline Caragana korshinskii & GU573848.1 & Wang et al. (2010) \\
\hline Chrysanthemum vestitum & EF633987.2 & Liu et al. (2008) \\
\hline Coffea arabica strain laurina & JQ687375.1 & Joet (2012) \\
\hline Cynodon dactylon & AY462118.1 & Xie and Wang (2003) \\
\hline Eucalyptus globulus & HM992944.1 & Baltierra and Krauskopf (2010) \\
\hline Glycine max & AY296651.1 & Li et al. (2005) \\
\hline Halimodendron halodendron & EU872018.1 & Yin et al. (2008) \\
\hline Helianthus annuus & AY508007.1 & Diaz-Martin et al. (2005) \\
\hline Hemarthria compressa & KC203598.1 & Chen et al. (2016) \\
\hline Hordeum brevisubulatum & AY728807.1 & Wan et al. (2004) \\
\hline Ipomoea batatas & KU578260.1 & Yang et al. (2016) \\
\hline Lilium longiflorum & MG811543.1 & Wu et al. (2018) \\
\hline Lycopersicon esculentum & AF500012.1 & Cheng et al. (2002) \\
\hline Malus prunifolia & JN204427.1 & Zhao et al. (2011) \\
\hline Malus sieversii & JQ790526.1 & Zhao et al. (2013) \\
\hline Manihot esculenta & JN615576.1 & An and Zhang (2011) \\
\hline Nicotiana tabacum & EU727156.1 & Liu and Feng (2008) \\
\hline Phyllostachys edulis & EU295483.1 & Liu et al. (2011) \\
\hline Poa pratensis & AY553331.1 & Shen et al. (2004) \\
\hline Populus euphratica & NM001304317.1 & Chen et al. (2009) \\
\hline Populus hopeiensis & GU207863.1 & Zhang et al. (2009) \\
\hline Populus trichocarpa & EF151454.1 & Yin et al. (2006) \\
\hline Saccharum arundinaceum & KJ670161.1 & Augustine and Subramonian (2014) \\
\hline Saccharum officinarum & JQ736812.1 & Liu et al. (2012) \\
\hline Schedonorus arundinaceus & AY436639.1 & Lv et al. (2003) \\
\hline Setaria italica & NM001310053.1 & Lata et al. (2010) \\
\hline Solanum lycopersicum & HQ698902.1 & Hichri et al. (2010) \\
\hline Solanum lycopersicum & NM001247830.1 & Aoki et al. (2010); Hichri et al. (2016) \\
\hline Solanum tuberosum & JN125858.1 & Bouaziz et al. (2012) \\
\hline Sophora moorcroftiana & KM527093.1 & Yao et al. (2016) \\
\hline Sorghum bicolor & DQ403725.1 & Bihani et al. (2006) \\
\hline Triticum aestivum & AY781345.1 & $\mathrm{Xu}$ et al. (2004) \\
\hline Triticum turgidum subsp. durum & GU785008.1 & Morran et al. (2010) \\
\hline Triticum urartu & KF731664.1 & Tavakol et al. (2014) \\
\hline Vigna unguiculata & JQ066264.2 & Sadhukhan et al. (2014) \\
\hline Zoysia japonica & KP676132.1 & Wie et al. (2015) \\
\hline
\end{tabular}




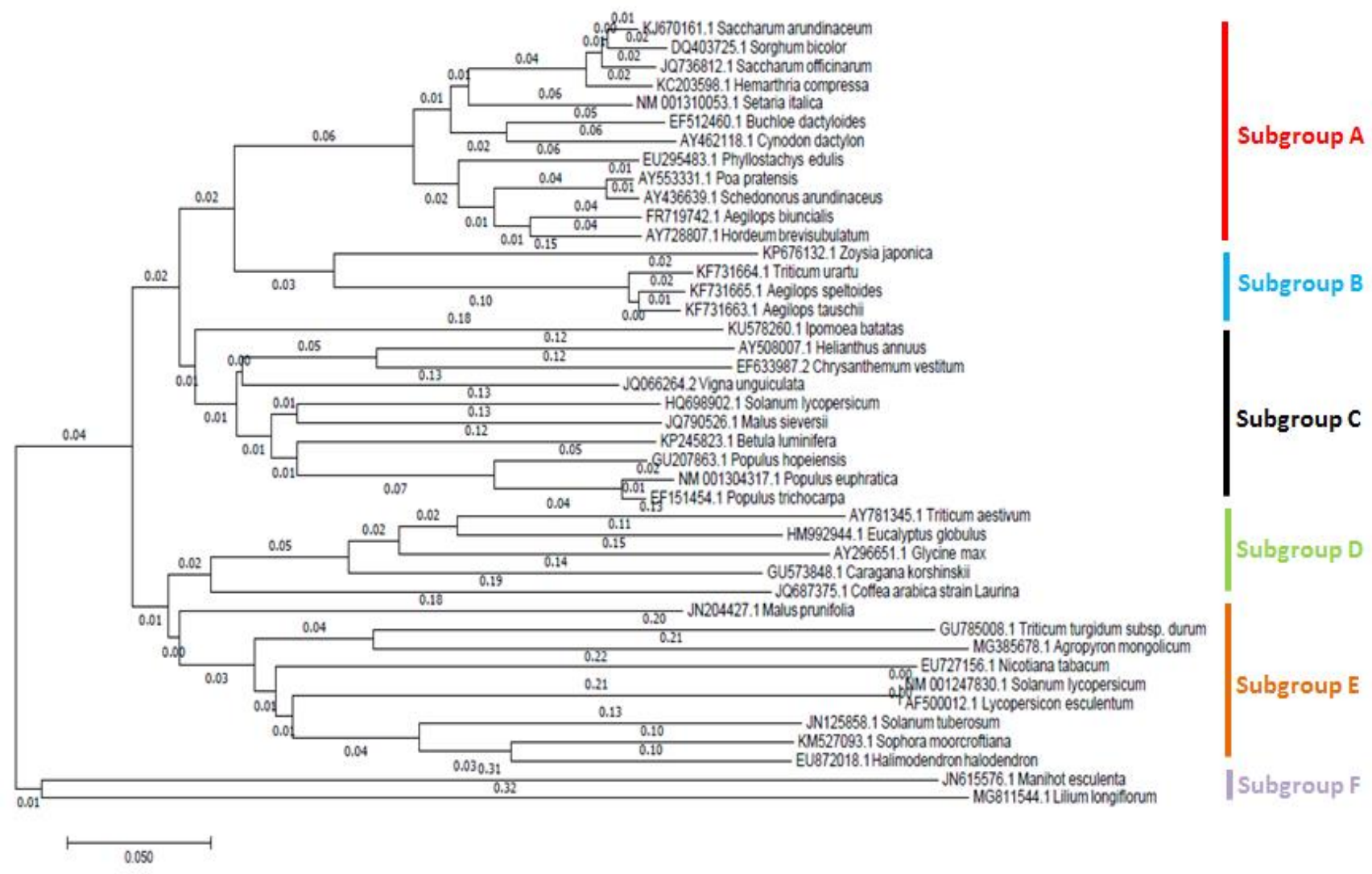

Figure 1. Phylogenetic tree of DREB2 gene in various plant species. The phylogenetic analysis was inferred using MEGA7 tool with the Neighbor-Joining method based on the DREB2 nucleotide sequences of 42 plant species. The tree is drawn to scale, with branch lengths (next to the branches) in the same units as those of the evolutionary distances used to infer the phylogenetic tree. The evolutionary distances were computed using the p-distance method and are in the units of the number of base differences per site.

By using multiple sequence alignment, protein homology analysis of DREB2 was performed in a number of monocotyledons and dicotyledons species (Figure 3). A highly conserved amino acid region is identified in the AP2/ERF domain having the motif sequence of YRGVRQRTWGKWVAEIREPNR in between NLS (Nuclear Localization Signal) and acidic regions.

Therefore, it can be concluded that the AP2 domain has been evolutionarily conserved in the plant species. It is also predicted that the AP2 binding domain shares a similar activity in between plant species to recognize the DRE sequence. Induced strongly by drought, DREB2 is thought to be a major transcription factor functioning under drought stress (Sakuma et al. 2006).

Several amino acid sequences can be generated from a single gene through the alternative splicing process which leads to expansion of the gene products for any given gene. The common events of AS are exon skipping (ES), intron retention (IR), and also the alternative of $5^{\prime}$ or $3^{\prime}$ splicing events (Kannan et al. 2018). Posttranscriptional mechanisms based on alternative splicing and RNA processing involved in responses to abiotic stress (Ding et al. 2014). Therefore, it has been predicted that AS plays a regulatory role in plant stress responses (Duque 2011). Many studies have reported the AS events in the DREB2 gene in various plants, but the functional regulation of this splicing process primarily depends on the species (Egawa et al. 2006; Liu et al. 2017). By using data obtained from INSDC (International Nucleotide Sequence Database Collaboration) and RefSeq as NCBI Reference Sequence Database, a number of AS events have been recognized in crop plant (Table 2). The alternative splicing of DREB2s is important for plants to repress functional protein accumulation because the high level of DREB2s causes growth defects. Due to its function as a post-transcriptional mechanism, AS process contributes to both transcriptome and proteome diversities which play as an important role in gene regulation and tissue-specific expression (Ramani et al. 2011). The basic role of the splicing mechanism is the recognition of introns and exons by the splicing machinery. The key component of AS process is the spliceosome that functions to recognize the splice sites. AS is tightly regulated by cis-elements within exons and surrounding introns as well as trans-acting factors that bind to these ciselements. The environmental stresses can induce AS process in pre-mRNAs of stress-responsive genes due to their sensitivity to the stress. In this case, the functions of their gene product are predicted by comparing the homology sequence with a known protein. 
A

Saccharum officinarum
Sorghum bicolor
Setaria italica
Hemarthria compressa
Poa pratensis
Aegilops biuncialis
Buchloe dactyloides

Saccharum officinarum Sorghum bicolor Setaria italica Hemarthria compressa Poa pratensis Aegilops biuncialis Buchloe dactyloides

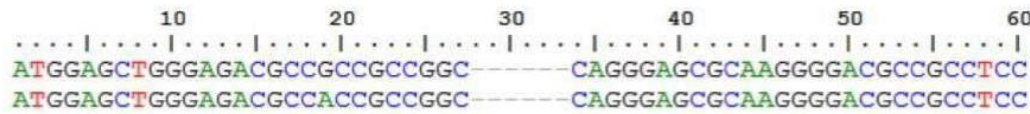
ATGGAGCTGGGAGACGCCACCGCCGGC---CAGGGAGCGCAAGGGGACGCCGCCTCC ATGGAGCTCGGAGACGCCGCCGCCGCCGCCGCCCAGGGAGGACCGCAAGGGGACGCCTCG

ATGGAGACCGGGGGTAGCAAGCGGGAAGGAGACTGC ATGGAGCGGGTGG

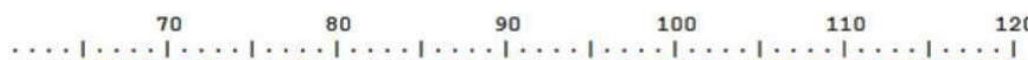
GGGGCCCTTGTCAGGAAGAAGAGGATGAGCAGGAAAAGCACTGGCCCTGACTCCATTGCT GGGGCCCTTGTCAGGAAGAAGAGGATGAGGAGGAAGAGCACTGGCCCTGACTCCATTGCC -ATGAGGAGGAAAAGCACTGGCCCTGACTCCATTGCT GGGGCCCTTGTCAGGAAGAAGAGGATGAGGAGGAAGAGCTCTGGCCCTGACTCCATTGCC -ATGTCCAGGAAGAAGAAAGTGCGCAGGAGAAGCACTGGTCCCGATTCGGTCGCT CCCGGGCAGGAAAGGAAGAAGAAAGTGCGCAGGAGAAGCACTGGTCCCGATTCGGTTGCT GGTGACCAAGTCAGGAAAAAGAGGATGCGAAGGAAAAGCACTGGCCCTGACTCGATCGCT
B

Saccharum officinarum Sorghum bicolor Setaria italica Hemarthria compressa Poa pratensis Aegilops biuncialis Buchloe dactyloides

Saccharum officinarum Sorghum bicolor Setaria italica Hemarthria compressa Poa pratensis Aegilops biuncialis Buchloe dactyloides

Saccharum officinarum Sorghum bicolor Setaria italica Hemarthria compressa Poa pratensis Aegilops biuncialis Buchloe dactyloides

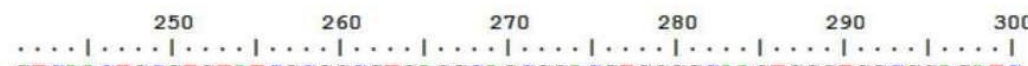
GTCAACTGCGTGTATCGCGGCGTGAGGCAGCGGACGTGGGGCAAGTGGGTGGCGGAGATC GTCAACTCCATGTACCGCGGTGTGAGGCAGCGGACGTGGGGCAAGTGGGTGGCGGAGATC GGGAATTGTCCGTACCGCGGCGTGAGGCAACGGACTTGGGGCAAATGGGTGGCCGAGATC GTCAACTGCGTGTACCGCGGCGTCAGGCAGCGGACGTGGGGCAAGTGGGTGGCGGAGATC TCAAATTGCAAATACCGTGGTGTGAGGCAGCGGACGTGGGGCAAATGGGTGGCTGAGATC TCAAACTGCGCTTACCGCGGTGTGAGGCAGAGGACGTGGGGCAAATGGGTTGCTGAGATC GGGAATTGTGTGTACCGCGGAGTGAGGCAGCGCACATGGGGCAAATGGGTGGCCGAGATC

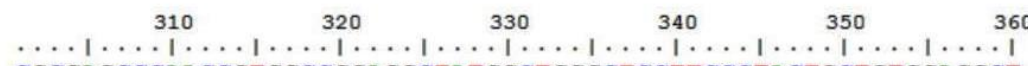
CGCGAGCCCAACCGTGGCCGGAGGCTATGGCTGGGCTCCTTCCCTACTGCTGTGGAGGCT CGCGAGCCCAACCGTGGCCGGAGGCTATGGCTGGGCTCCTTCCCTAATGCCGTGGAAGCT CGCGAGCCCAACCGTGGCAAGCGGCTGTGGCTAGGCTCATTCCCTACTGCTGTGGAGGCT CGCGAGCCCAACCGTGGTCGCAGGCTATGGCTGGGCTCCTTCCCTACTGCTGTGGAGGCT CGCGAGCCCAACCGTGGCAACCGGCTATGGCTTGGCTCATTCCCTACTGCGGTGGAAGCT CGTGAGCCCAACCGTGGCAATCGGCTGTGGCTTGGTTCGTTCCCTACCGCAGTCGAAGCT CGCGAGCCCAACCGCGGCAAGCGCTTATGGCTGGGCTCGTTCCCTACTGCTCTGGAGGCT

370
38 GCCCATGCATACGATGAGGCGGCAAAGGCGATGTATGGCCCCAAGGCACGTGTCAACTTC GCCCATGCATACGATGAGGCGGCAAAGGCCATGTATGGCCCCAAGGCACGTGTCAACTTC GCTCATGCATACGACGAGGCGGCAAAGGCGATGTATGGTCCCAAGGCACGTGTCAACTTT GCCCATGCATACGATGAGGCGGCAAAGGCGATGTATGGCCCCAGGGCACGTGTCAACTTC GCACATGCGTATGACGAGGCGGCAAGGGCAATGTATGGCGCCACAGCACGTGTCAACTTC GCACGTGCATATGATGATGCGGCAAGGGCAATGTATGGCGCCAAAGCACGTGTCAACTTC GCTCATGCATACGACGAGGCCGCGAGGGCAATGTATGGCCCCACGGCACGTGTCAACTTT
C

Saccharum officinarum
Sorghum bicolor
Setaria italica
Hemarthria compressa
Poa pratensis
Aegilops biuncialis
Buchloe dactyloides

Saccharum officinarum Sorghum bicolor Setaria italica Hemarthria compressa Poa pratensis Aegilops biuncialis Buchloe dactyloides

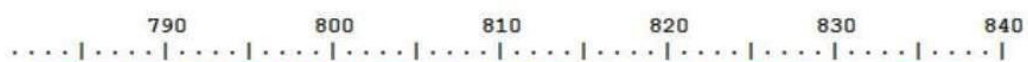
GAATTGAATGCTGATAAAAAAATTGAAGCACATGAAGAATACCATGATGGAGATGATGGG GAATTGAATGCTGATAAAAAAATTGAAGCACATGAAGAATACCATGATGGAGATGACGGG GAATTGAATGCAGATAAAAAAATTGAAGTACATGAAGAATGTCTTGGTGGAGATGATGGA GAATTGAATGCTGATAAAAAAATCGAAGCACATGAAGAATACCATGATGGAGATGATGGG GAATTGAGTGCTGATAGAAAAATGGAAGTACATGAAGAGTACCAAGATGGCGATGATGGG GAATTGAGTGCTGATGTAAAAACGGAAGCACATGAAGAGTACCAAGATGGTGATGATGGG GAATTGAATGCTGCTAAAACGATTGAGGTGCATGAAGAACACCAAGTTGGAGATGATGGG
\end{abstract}

Figure 2. Multiple alignment sequence (MSA) of cds DREB2 gene in Poaceae plants. The MSA method was performed by using BioEdit Sequence Alignment Editor. Poaceae plants used in this alignment analysis are Saccharum officinarum (JQ736812.1), Sorghum bicolor (DQ403725.1), Setaria italica (NM_001310053.1), Hemarthria compressa (KC203598.1), Poa pratensis (AY553331.1), Aegilops biuncialis (FR719742.1), and Buchloe dactyloides (EF512460.1). A. N-terminal domain of DREB2 gene, B. DNA binding domain of DREB2 gene, C. C-terminal region of DREB2 gene 


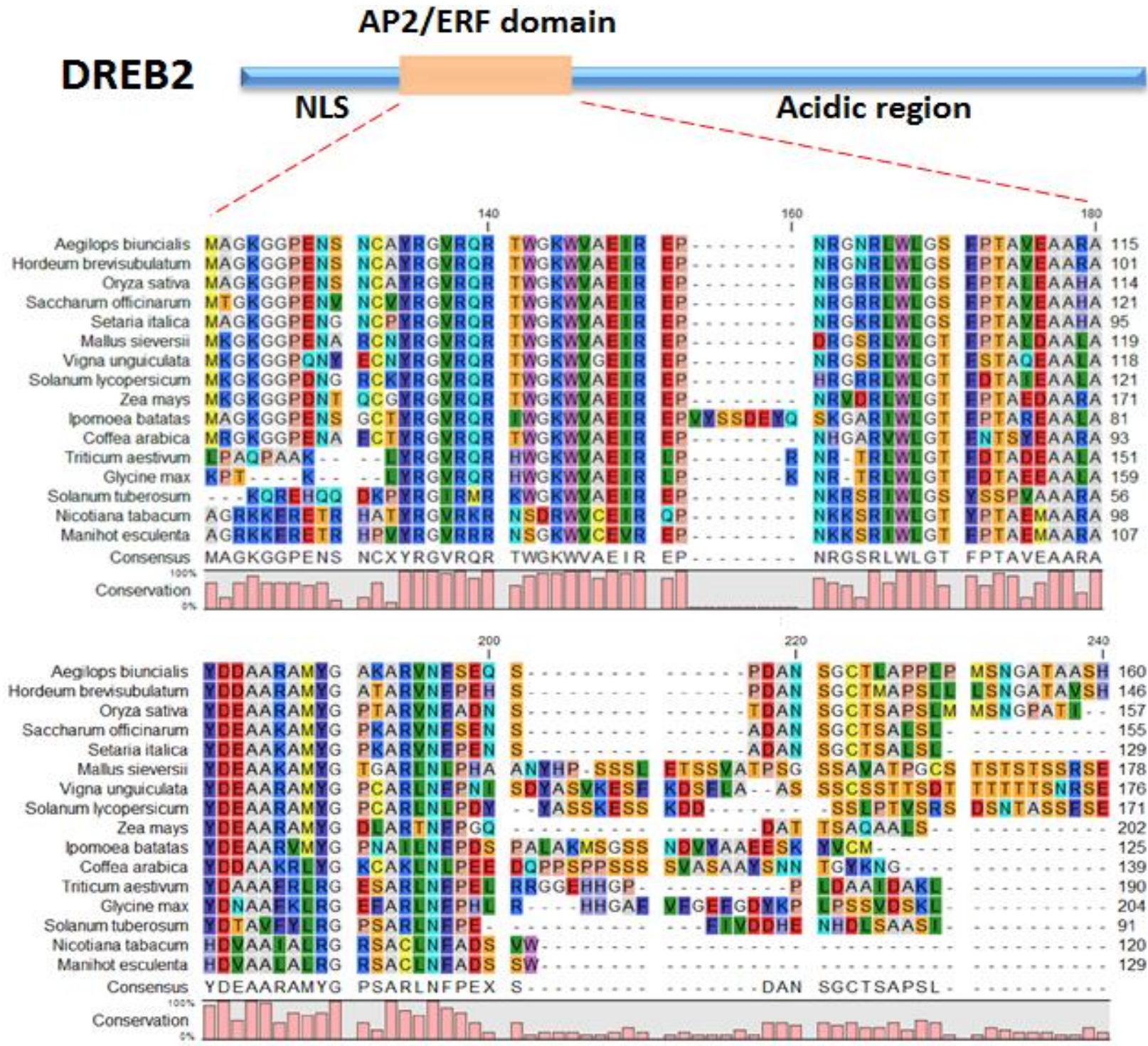

Figure 3. The highly conserved region of DREB2 protein. This conserved region belongs to AP2 domain that functions to bind to DRE of the down-stream targeted gene

The induced expression of a certain gene is a key event in helping the plant to set up an effective defensive state under stress conditions. Genes expressed under drought conditions are thought to function in the protecting cells from stress, not only by producing the metabolic proteins but also by regulating of down-stream genes for signal transduction cascades of the stress response (Lata and Prasad, 2011). Among the regulatory genes, TFs have acquired widespread attention due to their significant role in plant stress tolerant. Meanwhile, changes in the gene expression after given stress and the reprogramming of molecular machinery are also regulated by the transcription factor. In addition, a number of drought stress associated genes encoding transcription factors that in turn control other various genes, are also involved in diverse physiological and molecular reactions to drought stress.

Understanding molecular biology and biotechnical tools is a key factor underlying the modern efforts to develop transgenic stress tolerant plants. The DREB2 transcription factor is one of the most promising candidate genes for this purpose in conferring drought tolerance. Therefore, genetic modification of the expression of these regulatory genes can greatly influence plant stress tolerance due to their regulation in many downstream stress-responsive genes at a given time (Wang et al. 2016). As members of the AP2 family, DREB2 is known to control plant response to drought stress. Their overexpression can significantly improve stress tolerance in the transgenic plant (Sakuma et al. 2006). Transgenic Arabidopsis plants over-expressing ZmDREB2A showed improved drought stress tolerance (Qin et al. 2007). The transformation of GmDREB2 in tobacco plant under CAM35S promoter induced the drought stress tolerance plant having 4.5-fold higher proline content (Chen et al. 2007). Meanwhile, genetic transformation of tobacco plants overexpressing CpDREB2 exhibited an increased amount of proline and greater tolerance level to drought (Agarwal et al. 2010). 
Table 2. Alternative splicing of DREB2 in Zea mays and Sorghum bicolor plants

\begin{tabular}{|c|c|c|c|c|c|}
\hline Source & $\begin{array}{l}\text { CDS Region in } \\
\text { Nucleotide }\end{array}$ & Protein & Name & Organism & References \\
\hline INSDC & $\begin{array}{l}\text { JF915837.1 } \\
422-1168(+)\end{array}$ & AFI71290.1 & $\begin{array}{l}\text { Dehydration responsive element } \\
\text { binding protein } 2 \text { isoform } b\end{array}$ & Zea mays & Liu and Peng (2011) \\
\hline RefSeq & $\begin{array}{l}\text { NC_024466.2 } \\
96825865-96826611(+)\end{array}$ & NP_001292874.1 & $\begin{array}{l}\text { Dehydration-responsive element } \\
\text { binding protein } 2 \mathrm{~A} \text { isoform } 2\end{array}$ & Zea mays & Ware (2017) \\
\hline RefSeq & $\begin{array}{l}\text { NC_024466.2 } \\
96825865-96826611(+)\end{array}$ & XP_020397925.1 & $\begin{array}{l}\text { Dehydration-responsive element } \\
\text { binding protein } 2 \mathrm{~A} \text { isoform } \mathrm{X} 4\end{array}$ & Zea mays & Liu and Peng (2011) \\
\hline INSDC & $\begin{array}{l}\text { CM000784.4 } \\
96825865-96826611(+)\end{array}$ & AQK93332.1 & $\begin{array}{l}\text { Dehydration-responsive element- } \\
\text { binding protein } 2 \mathrm{~A}\end{array}$ & Zea mays & Ware (2017) \\
\hline RefSeq & $\begin{array}{l}\text { NC_024466.2 } \\
96823667-96826611(+)\end{array}$ & NP_001292873.1 & $\begin{array}{l}\text { Dehydration-responsive element } \\
\text { binding protein } 2 \mathrm{~A} \text { isoform } 1\end{array}$ & Zea mays & Jiao et al. (2017) \\
\hline NSDC & $\begin{array}{l}\text { JF915834.1 } \\
156-3100(+)\end{array}$ & AFI71285.1 & $\begin{array}{l}\text { Dehydration responsive element } \\
\text { binding protein } 2 \text { isoform c }\end{array}$ & Zea mays & Liu and Peng (2011) \\
\hline RefSeq & $\begin{array}{l}\text { NM_001112406.2 } \\
156-1115(+)\end{array}$ & NP_001105876.2 & $\begin{array}{l}\text { dehydration-responsive element } \\
\text { binding protein } 2 \mathrm{~A} \text { isoform } 3\end{array}$ & Zea mays & Gu et al. (2016) \\
\hline INSDC & $\begin{array}{l}\text { JF915841.1 } \\
137-1279(+)\end{array}$ & AFI71296.1 & $\begin{array}{l}\text { Dehydration responsive element } \\
\text { binding protein } 2 \text { isoform c }\end{array}$ & Sorghum bicolor & Liu and Peng (2011) \\
\hline INSDC & $\begin{array}{l}\text { JF915838.1 } \\
137-2893(+)\end{array}$ & AFI71291.1 & $\begin{array}{l}\text { Dehydration responsive element } \\
\text { binding protein } 2 \text { isoform c }\end{array}$ & Sorghum bicolor & Liu and Peng (2011) \\
\hline INSDC & $\begin{array}{l}\text { JF915840.1 } \\
400-1197(+)\end{array}$ & AFI71295.1 & $\begin{array}{l}\text { Dehydration responsive element } \\
\text { binding protein } 2 \text { isoform } b\end{array}$ & Sorghum bicolor & Liu and Peng (2011) \\
\hline INSDC & $\begin{array}{l}\text { JF915838.1 } \\
2096-2893(+)\end{array}$ & AFI71293.1 & $\begin{array}{l}\text { Dehydration responsive element } \\
\text { binding protein } 2 \text { isoform } b\end{array}$ & Sorghum bicolor & Liu and Peng (2011) \\
\hline INSDC & $\begin{array}{l}\text { JF915838.1 } \\
137-2893(+)\end{array}$ & AFI71292.1 & $\begin{array}{l}\text { Dehydration responsive element } \\
\text { binding protein } 2 \text { isoform a }\end{array}$ & Sorghum bicolor & Liu and Peng (2011) \\
\hline
\end{tabular}

DREB2 is one of the important genes for crop improvement either through engineering stress tolerance or through crop breeding strategies since it is being the major TF that binds to the cis-acting elements of most of the osmotic stress-inducible genes responsible for providing tolerance traits to the plants under stress conditions. Temporal gene expression studies of DREB2 gene in various crops have revealed that DREB2 is induced particularly by drought. The study of DREB2 in Oryza sativa showed that OsDREB2A transcript was induced within $24 \mathrm{~h}$ of dehydration (Dubouzet et al. 2003). The transcript level of Sorghum bicolor SbDREB2 increased at $1 \mathrm{~h}$ exposure to drought. Populus euphratica PeDREB2 also induced its expression under drought (Chen et al. 2009).

DREB2 thereafter can be used as a molecular marker to assist the selection technique for drought tolerance character in plants due to its activity as a master regulator of drought-responsive gene expression. However, the highly conserved AP2 domain can be deduced as considered sequence region to design specific primer in studying drought stress tolerance plant species based on the high induction in DREB2 gene expression.

\section{REFERENCES}

Agarwal P, Agarwal PK, Joshi AJ, Sopory SK, Reddy MK. 2010. Overexpression of PgDREB2A transcription factor enhances abiotic stress tolerance and activates downstream stress-responsive genes. Mol Biol Rep 37: 1125-1135.
Akhtar M, Jaiswal A, Taj G, Jaiswal JP, Qureshi MI, Singh NK. 2012. DREB1/CBF transcription factors: their structure, function, and role in abiotic stress tolerance in plants. J Genet 91: 385-395.

An D, Zhang,P. 2011. Transcriptome profiling of low temperature-treated cassava apical. Shanghai Center for Cassava Biotechnology, Institute of Plant Physiology \& Ecology, China.

Aoki K, Yano K, Suzuki A, Kawamura S, Sakurai N, Suda K, Kurabayashi A, Suzuki T, Tsugane T, Watanabe M, Ooga K, Torii M, Narita T, Shin-I T, Kohara Y, Yamamoto N, Takahashi H, Watanabe Y, Egusa M, Kodama M, Ichinose Y, Kikuchi M, Fukushima S, Okabe A, Arie T, Sato Y, Yazawa K, Satoh S, Omura T, Ezura H, Shibata D. 2010. Large-scale analysis of full-length cDNAs from the tomato (Solanum lycopersicum) cultivar Micro-Tom, a reference system for the Solanaceae genomics. BMC Genomics 11: 210. DOI: 10.1186/1471-2164-11-210.

Arana MV, Gallo LA, Vendramin GG, Pastorino MJ, Sebastiani F, Marchelli P. 2010. High genetic variation in marginal fragmented populations at extreme climatic conditions of the Patagonian Cypress Austrocedrus chilensis. Mol Phylogenet Evol 54 (3): 941-949

Augustine SM, Subramonian N. 2014. Overexpression of EaDREB2, a DREB2 transcription factor in the Erianthus arundinaceus (IK 76-81) and pyramiding of EaDREB2 and Pea DNA Helicase 45 (PDH45) enhances tolerance to multiple abiotic stresses in sugarcane. Sugarcane Breeding Institute, India.

Baltierra FA, Krauskopf E. 2010. Isolation and characterization of a cDNA encoding a dreb2 transcription factor from Eucalyptus globulus. Fundacion Ciencia para la Vida, Chile.

Bartels D, Sunkars R. 2005. Drought and salt tolerance in plants. Crit Rev Plant Sci 24: 23-58

Basu S, Ramegowda V, Kumar A, Pereira A. 2016. Plant adaptation to drought stress. F1000Research.5: F1000, Faculty Rev-1554. DOI: 10.12688/f1000research.7678.1.

Bihani PR, Char BR, Bhargava SS. 2006. Sorghum bicolor DREB2 genes. Biotechnology, Maharashtra Hybrid Seeds Company Ltd., India.

Bouaziz D, Pirrello J, Ben Amor H, Hammami A, Charfeddine M, Dhieb A, Bouzayen M, Gargouri-Bouzid R. 2012. Ectopic expression of dehydration responsive element binding proteins (StDREB2) confers higher tolerance to salt stress in potato. Plant Physiol Biochem 60C: 98-108. 
Chen J, Xia X, Yin W. 2009. Expression profiling and functional characterization of a DREB2-type gene from Populus euphratica. Biochem Biophys Res Commun 378: 483-487.

Chen M, Wang QY, Cheng XG, Xu ZS, Li LC, Ye XG, Xia LQ, Ma YZ. 2007. GmDREB2, a soybean DRE-binding transcription factor, conferred drought and high-salt tolerance in transgenic plants. Biochem Biophys Res Commun 353 (2): 299-305.

Chen Y, Huang L, Yan H, Zhang X, Xu B, Ma X. 2016. Cloning and characterization of an ABA-independent DREB transcription factor gene, HcDEB2, in Hemarthria compressa. Hereditas 153: 3. DOI: 10.1186/s41065-016-0008-y.

Cheng XG, Hou YX, Sun S, Chen F, Liu,Q. 2002. Expression of LeDREB1 gene related to tolerance of stress in tomato. Department of Biological Science and Biotechnology, Tsinghua University, China.

Constanzo S, Jia Y. 2010. Sequence variation at the rice blast gene $P i-$ $\mathrm{km}$ locus: implications for the development of allele specific markers. Plant Sci. 178: 523-530.

Diaz-Martin J, Almoguera C, Prieto-Dapena P, Espinosa JM, Jordano J. 2005. Functional interaction between two transcription factors involved in the developmental regulation of a small heat stress protein gene promoter. Plant Physiol 139 (3): 1483-1494.

Ding F, Cui P, Wang ZY, Zhang SD, Ali S, Xiong LM. 2014. Genomewide analysis of alternative splicing of pre-mRNA under salt stress in Arabidopsis. BMC Genomics 15 (1): 431. DOI: 10.1186/14712164-15-431.

Dubouzet JG, Sakuma Y, Ito Y, Kasuga M, Dubouzet EG, Miura S, Seki M, Shinozaki K, Yamaguchi-Shinozaki K. 2003. OsDREB genes in rice, Oryza sativa L., encode transcription activators that function in drought-, high-salt-, and cold-responsive gene expression. Plant J 33: 751-763.

Duque P. 2011. A role for SR proteins in plant stress responses. Plant Sign Behav 6: 49-54.

Egawa C, Kobayashi F, Ishibashi M Nakamura T, Nakamura C, Takumi S. 2006. Differential regulation of transcript accumulation and alternative splicing of a DREB2 homolog under abiotic stress conditions in common wheat. Genes Genet Syst 81: 77-91.

Gao JP, Chao DY, Lin HX. 2008. Toward understanding molecular mechanisms of abiotic stress responses in rice. Rice 1 (1): 36-51.

Gu L, Zhang Y, Zhang M, Li T, Dirk LM, Downie B, Zhao T. 2016. ZmGOLS2, a target of transcription factor ZmDREB2A, offers similar protection against abiotic stress as ZmDREB2A. Plant Mol Biol 90 (1-2): 157-170.

Gonzalez-Martı'nez SC, Elhan Ersoz E, Brown GR, Wheeler N, Neale DB. 2006. DNA sequence variation and selection of tag singlenucleotide polymorphisms at candidate genes for drought-stress response in Pinus taeda L. Genetics 172: 1915-1926.

Hall TA. 1999. BioEdit: a user-friendly biological sequence alignment editor and analysis program for Window 95/98/NT. Nucleic Acids Symp Ser 41: 95-98.

Hichri I, Ghanem ME, Lutts S. 2010. Isolation of transcription factors from tomato (Solanum lycopersicum) salt-stressed roots. Earth and Life Institute (ELI), Groupe de Recherche en Physiologie Vegetale (GRPV), UCL-Belgium.

Hichri I, Muhovski Y, Clippe A, Zizkova E, Dobrev PI, Motyka V, Lutts S. 2016. SIDREB2, a tomato dehydration-responsive element-binding 2 transcription factor, mediates salt stress tolerance in tomato and Arabidopsis. Plant Cell Environ 39 (1): 62-79.

Hirayama T, Shinozaki K. 2010. Research on plant abiotic stress responses in the post-genome era: Past, present, and future. Plant J 61 (6): 1041-1052.

Hu XY, Yang QC, Hu TM, Li M, Kang JM. 2007. Isolation and characterization of a cDNA encoding a DREB2 transcription factor from buffalo grass (Buchloe dactyloides). The Chinese Academy of Agricultural Sciences, Institute of Animal Sciences, China.

Jan AT, Singhal P, Haq Q. 2012. Plant abiotic stress: Deciphering remedial strategies for emerging problem. J Plant Interact 8: 1-12. 10.1080/17429145.2012.702226.

Jiao Y, Peluso P, Shi J, Liang T, Stitzer MC, Wang B, Campbell MS, Stein JC, Wei X, Chin CS, Guill K, Regulski M, Kumari S, Olson A, Gent J, Schneider KL, Wolfgruber TK, May MR, Springer NM, Antoniou E, McCombie WR, Presting GG, McMullen M, Ross-Ibarra J, Dawe RK, Hastie A, Rank DR, Ware D. 2017. Improved maize reference genome with single-molecule technologies. Nature 546 (7659): 524-527. DOI: 10.1038/nature22971.
Joet T. 2012. Transcriptome analysis of coffee seed development. DIADE, IRD, France.

Kannan S, Halter G, Renner T, Waters ER. 2018. Patterns of alternative splicing vary between species during heat stress, AoB Plants 10: 2. DOI: 10.1093/aobpla/ply013.

Khan MS. 2011. The Role of Dreb Transcription factors in abiotic stress tolerance of plants. Biotechnol Biotechnol Equip 25 (3): 2433-2442. DOI: 10.5504/BBEQ.2011.0072

Lata C, Bhutty S, Bahadur RP, Majee M, Prasad M. 2011. Association of a SNP in a novel DREB2-like gene SiDREB2 with stress tolerance in foxtail millet [Setaria italica (L.)]. J Exp Bot. DOI: 10.1093/jxb/err016.

Lata C, Dewan S, Prasad M. 2010. SNP identification and development of a functional marker for a novel DREB2-like gene SiDREB2 in foxtail millet (Setaria italica L.). Plant Molecular Biology, National Institute of Plant Genome Research, India.

Lata C, Prasad M. 2011. Role of DREBs in regulation of abiotic stress responses in plants. J Exp Bot 62: 4731-4748.

Li XP, Tian AG, Luo GZ, Gong ZZ, Zhang JS, Chen SY. 2005. Soybean DRE-binding transcription factors that are responsive to abiotic stresses. Theor Appl Genet 110 (8): 1355-1362.

Liu GS, Peng XJ. 2011. The alternative splicing of SbDREB2. Institute of Botany, the Chinese Academy of Sciences, Beijing, China.

Liu L, Zhao H, He CF, Bai R, Yao A, Li LB. 2011. Isolation and characterization of a gene for a DREB transcription factor from Phyllostachys edulis induced by drought. J Hort Sci Biotechnol 86 (2): 166-174.

Liu L, Zhu K, Yang Y, Wu J, Chen F, Yu D. 2008. Molecular cloning, expression profiling and trans-activation property studies of a DREB2-like gene from chrysanthemum (Dendranthema vestitum). J Plant Res. 121 (2): 215-226. DOI: 10.1007/s10265-007-0140-x.

Liu M, Wang AQ, Niu JQ, Huang WJ. 2012. Cloning and expression analysis of DREB2 gene in sugarcane. College of Agricultural, China.

Liu Q, Kasuga M, Sakuma Y, Abe H, Miura S, Yamaguchi-Shinozaki K, Shinozaki, K. 1998. Two transcription factors, DREB1 and DREB2, with an EREBP/AP2 DNA binding domain separate two cellular signal transduction pathways in drought- and low-temperatureresponsive gene expression, respectively, in Arabidopsis. Plant Cell 10 (8): 1391-1406.

Liu W, Feng F. 2008. Cloning and functional analysis of DREB transcription factors in Nictotiana tabacum. College of Life Science, Henan Agricultural University, China

Liu Z, Yuan G, Liu S, Jia J, Cheng L, Qi D, Shen S, Peng X, Liu G. 2017. Identified of a novel cis-element regulating the alternative splicing of LCDREB2. Scientific 7: 46106. DOI: 10.1038/srep46106 1

Lucas S, Durmaz E, Akpinar BA, Budak H. 2011. The drought response displayed by a DRE-binding protein from Triticum dicoccoides. Plant Physiol Biochem 49: 346-351. DOI: 10.1016/j.plaphy.2011.01.016

Lv SY, Li YF, Shen SH, Jing YX, Ma LQ, Zhou XJ, Ren Q. 2003. Isolation and analysis of DREB2 gene from Festuca arundinacea. Research Center of Plant Molecular and Developmental Biology, Institute of Botany, Chinese Academy of Sciences, China.

Mitsuda N, Ohme-Takagi M. 2009. Functional analysis of transcription factors in Arabidopsis. Plant Cell Physiol 50: 1232-1248. DOI: 10.1093/pcp/pcp075

Morran S, Eini O, Pyvovarenko T, Parent B, Singh R, Ismagul A, Eliby S, Shirley N, Langridge P, Lopato S. 2010. Improvement of stress tolerance of wheat and barley by modulation of expression of DREB/CBF factors. Plant Biotechnol J 9 (2): 230-249.

Mun BG, Lee SU, Park EJ, Kim HH, Hussain A, Imran QM, Lee I, Yun BW. 2017. Analysis of transcription factors among differentially expressed genes induced by drought stress in Populus davidiana. 3 Biotech 7 (3): 209. DOI: 10.1007/s13205-017-0858-7

Nakashima K, Shinwar ZK, Sakuma Y, Seki M, Miura S, Shinozaki K, Yamaguchi-Shinozaki K. 2000. Organization and expression of two Arabidopsis DREB2genes encoding DRE-binding proteins involved in dehydration- and high salinity-responsive gene expression. Plant Mol Biol 42: 657-665.

Nuruzzaman M, Sharoni AM, Kikuchi S. 2013. Roles of NAC transcription factors in the regulation of biotic and abiotic stress responses in plants. Front Microbiol 4: 248. DOI: 10.3389/fmicb.2013.00248

Pomponio MF. Torales S, Gallo LA, Pastorino MJ, Machello P, Cervera MT, Poltri SM. 2013. DNA sequence variation of drought response candidate gene in Austrocedrus chilensis. Electr J Biotechnol 16: 3-3. DOI: $10.2225 /$ vol16-issue2-fulltext-7. 
Qin F, Kakimoto M, Sakuma Y, Maruyama K, Osakabe Y, Tran LS, Shinozaki K, Yamaguchi-Shinozaki K. 2007. Regulation and functional analysis of ZmDREB2A in response to drought and heat stresses in Zea mays L. Plant J 50: 54-69.

Ramani AK, Calarco JA, Pan Q, Mavandadi S, Wang Y, Nelson AC, Lee LJ, Morris Q, Blencowe BJ, Zhen M, Fraser AG. 2011. Genome-wide analysis of alternative splicing in Caenorhabditis elegans. Genome Res 21: 342-348

Riechmann JL, Heard J, Martin G, Reuber L, Jiang C, Keddie J, Adam L, Pineda O, Ratcliffe OJ, Samaha RR, Creelman R, Pilgrim M, Broun P, Zhang JZ, Ghandehari D, Sherman BK, Yu G. 2000. Arabidopsis transcription factors: genome-wide comparative analysis among eukaryotes. Science 290 (5499): 2105-2110.

Sadhukhan A, Kobayashi Y, Kobayashi Y, Tokizawa M, Yamamoto YY, Iuchi S, Koyama H, Panda SK, Sahoo L. 2014. VuDREB2A, a novel DREB2-type transcription factor in the drought-tolerant legume cowpea, mediates DRE-dependent expression of stress-responsive genes and confers enhanced drought resistance in transgenic Arabidopsis. Planta 240 (3): 645-664.

Sakuma Y, Liu Q, Dubouzet JG, Abe H, Shinozaki K, YamaguchiShinozaki K. 2002. DNA-binding specificity of the ERF/AP2 domain of Arabidopsis DREBs, transcription factors involved in dehydration and cold-inducible gene expression. Biochem Biophys Res Commun 290: 998-1009.

Sakuma Y, Maruyama K, Qin F, Osakabe Y, Shinozaki K, YamaguchiShinozaki K. 2006. Dual function of an Arabidopsis transcription factor DREB2A in water-stress-responsive and heat-stress-responsive gene expression. Proc Natl Acad Sci USA 103: 18822-18827.

Shafeinie A, Mohammadi V, Alizadeh H, Zali AA. 2014. Overexpression of Arabidopsis Dehydration-Responsive Element-Binding Protein 2A Confers Tolerance to Salinity Stress to Transgenic Canola. Pakistan J Biol Sci 17: 619-629.

Shen S, Ren Q, Tang M, Liang Y, Jin Y, Liu G, Lv S, Zhou X, Shun J, Liu J. 2004. A DREB gene in Poa pratensis. Photosynthesis Research Center, Institute of Botany, Chinese Academy of Sciences, China.

Shinozaki K, Yamaguchi-Shinozaki K. 2007. Gene networks involved in drought stress response and tolerance. J Exp Bot 58 (2): .221-227.

Tamura K, Dudley J, Nei M, Kumar S. 2007. MEGA4: Molecular Evolutionary Genetics Analysis (MEGA) software version 4.0. Mol Biol Evol 24: 1596- 1599.

Tavakol E, Sardaro ML, Shariati JV, Rossini L, Porceddu E. 2014. Isolation, promoter analysis and expression profile of Dreb2 in response to drought stress in wheat ancestor. Gene 549 (1): 24-32.

Wan S, Lu SY, Li YF. 2004. Isolation and analysis of DREB2 gene from Hordeum brevisubulatum. Research Center of Plant Genetic Engineering, Changchun University of Agricultural and Animal Science, China.

Wang H, Wang H, Shao H, Tang X. 2016. Recent advances in utilizing transcription factors to improve plant abiotic stress tolerance by transgenic technology. Front. Plant Sci 7: 67. DOI 10.3389 /fpls.2016.00067.

Wang X, Dong J, Liu Y, Gao H. 2010. A novel Dehydration-Responsive Element-Binding Protein from Caragana korshinskii is involved in the response to multiple abiotic stresses and enhances stress tolerance in transgenic tobacco. Plant Mol Biol Rep 28 (4): 664-675.

Ware D. 2017. Maize Genome Sequencing Project. Cold Spring Harbor Laboratory/USDA-ARS, USA

Wie S, Ke X, Wu Q, Li J. 2015. College of Life and Environmental Science, Minzhu University of China, China.
Wu Z, Liang J, Zhang S, Zhang B, Zhao Q, Li G, Yang X, Wang C, He J, Yi M. 2018. A canonical DREB2-type transcription factor in lily is post-translationally regulated and mediates heat stress response. Front Plant Sci 9: 243. DOI: 10.3389/fpls.2018.00243.

Xia YLR, Bai G, Siddique KHM, Varshney RK, Baum M, Yan G, Guo P. 2017. Genetic variations of HvP5CS1 and their association with drought tolerance related traits in barley (Hordeum vulgare L.). Sci Rep 7: 7870. DOI: 10.1038/s41598-017-08393-0.

Xie YL, Wang ZZ. 2003. Isolation of a Bermuda grass cDNA encoding a DREB-like protein induced by high salt. Department of Biological Sciences and Biotechnology, Tsinghua University, China.

Xu ZS, Ma YZ, Cheng XG, Chen M, Li LC. 2004. Isolation and functional identification of AP2/EREBP transcriptional factor from wheat under abiotic stress. Institute of Crop Science, Chinese Academy of Agricultural Science, China.

Yamaguchi-Shinozaki K, Shinozaki K. 2005. Organization of cis-acting regulatory elements in osmotic- and cold-stress-responsive promoters. Trends Plant Sci 10: 88-94.

Yang H, Zhao X, Lu G, Lin S, Zheng J, Wu L, Shen Y. 2016. Molecular characterization of a cDNA encoding DRE-binding transcription factor from low-temperature treated storage root of sweet potato. School of Agriculture and Food Science, Zhejiang Agricultural \& Forestry University, China.

Yang W, Huang X, Zhang A. 2010. Isolation and characterization of CBF genes from Aegilops biuncialis. IGDB, Chinese Academy of Sciences, China.

Yao WJ, Fu YR, Zhang YF, Li HE. 2016. Cloning of four DREB genes from Tibetan Sophora moorcroftiana and analysis of their expression during abiotic stress. J For Res 27 (3): 675-683.

Yi L, Chen C, Yin S, Li H, Li Z, Wang B, King GJ, Wang J, Liu K. 2018. Sequence variation and functional analysis of a FRIGIDA orthologue (BnaA3.FRI) in Brassica napus. BMC Plant Biol 18 (1): 32. DOI: 10.1186/s12870-018-1253-1.

Yin CC, Wie L, Wie YH, Wu YM. 2008. Molecular cloning and functional analysis of a novel gene encoding the DREB2 protein from salt tree (Halimodendron halodendron). Biotechnology Research Institute, Chinese Academy of Agricultural Sciences, China.

Yin WL, Xia XL, Chen JH. 2006. Genome-wide analysis of Populus DRE-binding proteins. College of Biological Sciences and Technology, Beijing Forestry University, China.

Yu X, Bai G, Liu S, Luo N, Wang Y, Richmond DS, Pijut PM, Jackson SA, Yu J, Jiang Y. 2013. Association of candidate genes with drought tolerance traits in diverse perennial ryegrass accessions. J Exp Bot 64 (6): 1537-1551. DOI: $10.1093 / \mathrm{jxb} / \mathrm{ert018}$

Yu D, Han B. 2017. Institute of Grassland Research, Chinese Academy of Agricultural Sciences, China.

Zhang J. 2014. Characterization of new and drought stress responsive microRNAs in Betula luminifera. Forest Genetics, Zhejiang Agriculture and Forestry University, China.

Zhang ZY, Wang ZL, An XM, Ren YY. 2009. Characterization of two highly similar DREB2-related genes, PhDREB2a and PhDREB2b, in Populus hopeiensis. National Engineering Laboratory for Tree Breeding, Beijing Forestry University, China.

Zhao K, Shen X, Yuan H, Liu Y, Liao X, Wang Q, Liu L, Li F, Li T. 2013. Isolation and characterization of Dehydration-Responsive Element-Binding Factor 2C (MsDREB2C) from Malus sieversii Roem. Plant Cell Physiol 54 (9): 1415-1430.

Zhao T, Ma F, Liang D, Liu J. 2011. Dept of Pomology, Northwest A\&F University, China. 